\title{
nature
}

\section{Affirmative action ignored}

A report from the White House valuably highlights the chronic difficulties in the United States in involving minority groups in science and technology. But it wrongly skirts around a key issue in alleviating a potential crisis.

$\mathrm{T}$ wenty months ago, President Bill Clinton directed his National Science and Technology Council (NSTC) to find ways to redress a troubling fact: women, minorities and the disabled are "grossly under-represented" in the scientific, engineering and technical workforce. The NSTC is the main body through which the president coordinates such policy across the federal government. As such, it is made up of the vice-president, along with the chiefs of the departments that conduct significant amounts of science. If any group has the power to make strong recommendations addressing this serious problem, it is the NSTC.

Instead, in a report compiled by less senior bureaucrats and issued last week over its signature, the NSTC has delivered a toothless series of recommendations that essentially ask federal agencies to continue doing what they are already doing, only more so (see page 800 ). But the report fails to make significant inroads into a problem of such rapidly growing proportions that the report itself predicts "devastating" consequences for the US economy and US scientific leadership by 2050 if it is not tackled now. Put bluntly, as the number of young white men choosing to enter postgraduate scientific education in the United States declines, the gap is being filled by immigrants, while fast-growing minority populations within the United States stand on the sidelines. The report estimates that, if the same fraction of 22 -year-olds in each ethnic group graduate with bachelors' degrees in science and engineering in 2050 as did in 1995, the science, technology and engineering workforce would decline by nearly ten per cent. Yet the need for such workers can only grow.

Remedial action needs to take account of deep-seated factors in US society. Gross inequalities in public education result in oftenabysmal standards in urban areas where minorities live. Pervasive residential segregation and low levels of intermarriage further exclude racial minorities from prestigious areas of national life, such as scientific research. Women, like non-whites, are deterred by a lack of role models in science. And financial instability among graduate students and postdocs discourages those, including most minorities, whose need for financial security is greatest.

Against such a background, there is a need to consider new approaches to affirmative action. As the report rightly points out, a series of major court decisions and voter referendums have, since 1995, reflected an increasingly hostile climate towards policies such as those that use racial and gender preferences in university admissions. The results can only exacerbate the science-workforce problem. In California, voters banned such preferences in 1996. This year, 34 per cent fewer black, Hispanic and Native-American undergraduate students will be admitted to the University of California at Berkeley; 28 per cent fewer will be accepted at the University of California at Los Angeles.

The government's science agencies have had affirmative-action problems of their own. The National Science Foundation was sued in 1997 by a South Carolina maths graduate who alleged that the foundation's Minority Graduate Research Fellowship programme unfairly discriminated against him by making him ineligible for a fellowship on the grounds that he was white. In a similar lawsuit brought that year against the National Institutes of Health, a white teenager claimed she was excluded from a summer camp designed to attract minority students to careers in biomedicine.

The Clinton administration has made marked progress in terms of its own female and minority appointments, for which it should be commended. Even in a climate so hostile to affirmative action, it is regrettable that the NSTC did not recommend more decisive moves in that direction to promote diversity in science and technology.

\section{Wellcome in the dock}

\section{Power brings unfair criticism, fair scrutiny and a need for transparency.}

$\mathrm{t}$ can be hard to feel sorry for the Wellcome Trust. With an asset base of about $\mathfrak{E} 13$ billion (US\$21 billion), it awards grants amounting to about $£ 600$ million a year, putting its support for biomedical research at almost twice that of Britain's Medical Research Council. It is therefore perhaps not surprising that the trust should be looked on with envy by other medical research charities. Or that it now plays a critical, and thus closely observed, role in supporting British research.

That very power has brought with it the requirement not only to act responsibly, but also to be seen to do so. That need has been put sorely to the test in recent weeks, not least by management and financial reviews of problems at the Wellcome Trust Centre for the Epidemiology of Infectious Diseases at the University of Oxford (see page 802). To its credit, the trust has acknowledged its own share of responsibility for lax management and oversight. But how did things get so out of hand?
Also controversial has been the trust's role in the decision on the siting of Britain's new synchrotron radiation facility, Diamond. Many have argued that the trust's offer to cover a substantial proportion of the initial costs, however generous, has allowed it to exercise excessive influence over the decision to locate the facility at the Rutherford Appleton Laboratory outside Oxford, and that this decision reflected, in some undefined way, the self-interest of key trust individuals. That criticism is surely unfair: all the signs are that the real dispute was one inside the government over how far politics should be allowed to determine decisions on scientific investment.

Exposure to brickbats is one of the costs of a high public profile. Maintaining confidence in these situations is not always easy. Greater transparency to public scrutiny has become the preferred route of many government institutions. The Wellcome Trust is already moving in this direction. Recent events should encourage it to move further - and faster. 